\title{
Heberden Society:
}

\section{Combined Meeting, September 1982}

A combined Annual Provincial Meeting of the Heberden Society, the British Association for Rheumatology and Rehabilitation, the Royal Society of Medicine Section of Rheumatology and Rehabilitation, and the Irish Society of Rheumatology and Rehabilitation was held at Robinson College, Cambridge, on 23-24 September 1982 by kind invitation of Dr B. Hazleman. The four chairmen of the meeting were Dr C. Hawkins, Dr A. Yates, Dr E. Hamilton, and Dr M. W. J. Boyd.

The following papers and posters were presented.

Spina bifida occulta is of significance in back injuries in sport. S. M. Lachmann. Sports Injury Clinic, Department of Rheumatology, Addenbrooke's Hospital, Hills Road, Cambridge CB2 2QQ.

Sports injuries are often dismissed as trivial and selfinflicted. Back injuries interfere with an individual's capacity for work and may cause long-term sequelae. Spina bifida occulta (SBO) is cited in many radiological texts as of no clinical significance and hence may not be mentioned in $x$-ray reports.

Two hundred and ten cases of lumbar and referred pain were seen in a total of 2269 sports injuries. Investigation included full clinical examination and $x$-rays of lumbar region. Clinical diagnoses are given in Table 1.

One hundred and twenty three had radiological abnormalities, some more than one-see Table 2 . In this series (average age 25) 55/210 had SBO. This

Table 1

\begin{tabular}{llll}
\hline PID & $\begin{array}{l}\text { Spondylolysisl } \\
\text { spondylolisthesis }\end{array}$ & Scheuermann's & $\begin{array}{l}\text { 'Back } \\
\text { strain' }\end{array}$ \\
\hline 95 & 10 & $\begin{array}{l}\text { Acute 4 } \\
\text { Old } 30\end{array}$ & 86 \\
\hline
\end{tabular}

Table 2

\begin{tabular}{llll}
\hline SBO & $\begin{array}{l}\text { Degenerative } \\
\text { disc disease }\end{array}$ & $\begin{array}{l}\text { Spondylolysis/ } \\
\text { spondylolisthesis }\end{array}$ & Scheuermann's \\
\hline 55 & 25 & 10 & 34 \\
\hline
\end{tabular}

PID = prolapsed intervertebral disc. $\mathrm{SBO}=$ spina bifida occulta. was compared with 94 consecutive older patients referred to outpatients with backache. Five had SBO. $\left(\chi^{2}\right.$ test $\left.\mathrm{p}<<0.001\right)$. The incidence of SBO is highest in sports with heavy spinal loading.

Conclusions. (1) Back pain due to sports injuries has a high incidence of radiological abnormalities. It should be properly investigated and treated and the patient advised about future activities. (2) Heavy loading of immature spines may predispose to Scheuermann's disease. (3) SBO is of significance as a cause of back pain in this group, probably for mechanical reasons.

Infection and interferon production in systemic juvenile chronic arthritis-A prospective study. A. de Vere-Tyndall, Teresa Bacon, Ruth Parry, ${ }^{*}$ D. A. J. Tyrrell, ${ }^{*}$ A. M. Denman, Barbara M. Ansell. *Division of Rheumatology and Communicable Diseases, CRC, Northwick Park Hospital, Harrow.

Historically exacerbations of systemic juvenile chronic arthritis are frequently preceded by intercurrent infection. A prospective study has been performed to investigate this and look at the children's ability to deal with such infection. Nineteen patients with systemic JCA were sequentially investigated for up to 15 months (mean 6.6). They were seen monthly as well as during episodes of infection or disease flare. Each time clinical assessment was accompanied by viral, bacterial, and mycoplasma screening. Blood investigations included immunoglobulin levels, antibody titres to a panel of microbial antigens, and serial neutralising antibody titres against any viruses isolated. Interferon (IFN) in serum and nasal aspirate was assayed and the in vitro IFN $\alpha$ and $\gamma$ production by lymphocytes measured. Identical single studies were performed on 24 children with noninflammatory complaints.

Most flares were preceded by an infection (Table $3)$. This was highly significant $\left(\chi^{2}=20 \cdot 14, p<0 \cdot 001\right)$. No gross differences were noted in specific antibody titres between patients and control. Interferon responses were not defective, although sequential in vitro IFN $\alpha$ and $\gamma$ responses fluctuated considerably in the same patients. 
Table 3

\begin{tabular}{lllc}
\hline & Flares & & \\
\cline { 2 - 4 } & Total & Systemic & Joints only \\
\hline Total & 24 & 14 & 10 \\
$\begin{array}{l}\text { Preceded by infection } \\
\text { Agent identified }\end{array}$ & 16 & 10 & 6 \\
& Herpes simplex virus, & Herpes simplex virus, & streptococcus (3) \\
\hline
\end{tabular}

The effect of different corticosteroid regimens on the hypothalmic-pituitary-adrenal (HPA) axis and linear growth in juvenile chronic arthritis. M. A. Byron, J. Jackson, B. M. Ansell. Juvenile Rheumatism Unit, Canadian Red Cross Memorial Hospital, Taplow, Maidenhead, Berkshire.

In the management of juvenile chronic arthritis (JCA) corticosteroid therapy may still be required. Daily divided doses suppress the HPA axis, preventing normal responsiveness to stress as well as stunting growth in height.

Linear growth in 36 children with JCA on various corticosteroid regimens has been recorded. In particular a group of 7 children who commenced alternate-day corticosteroids under the age of 5 were compared with matched controls. The HPA axis was assessed in 20 , and we confirmed that resting cortisols correlate well with response to insulininduced-hypoglycaemia (insulin tolerance test-ITT).

Three types of corticosteroid regimen were identified. Those on daily steroid were clearly suppressed and not growing. Those who had received only alternate-day steroid were not suppressed and growth was occurring. There was no significant difference between children who commenced alternate-day corticosteroid before the age of 5 and their control group. Those on alternate-day steroid who had received daily steroid in the past showed no clear pattern. Suppression depended on dosage and duration of therapy. Growth appeared to resume before HPA suppression was reversed.

We suggest that daily divided doses of corticosteroid should not be used. Whenever possible a single morning dose (up to $20 \mathrm{mg}$ ) alternate-day regimen should be employed, as on this regimen reduction of HPA function and growth retardation are minimal even in small children. True resting cortisols are a reliable guide to the recovery of the HPA axis when converting from daily to alternate-day therapy.

Jejuno-ileal bypass arthropathy. J. P. Delamere, R. M. Baddeley, ${ }^{*}$ K. W. Walton. Department of Investigative Pathology, The Medical School,
University of Birmingham, and ${ }^{*}$ Department of Surgery, General Hospital, Birmingham.

The formation of a jejuno-ileal bypass (JIB), while being effective is procuring weight reduction, is associated with numerous complications including an arthropathy. The degree to which these postoperative articular symptoms reflect preoperative degenerative joint disease, the metabolic consequence of rapid weight reduction, or osteomalacia (a known postoperative complication) are matters which have been the subject of recent debate. To answer these questions we have investigated 3 groups of patients: group (1) 107 JIB patients in whom osteomalacia was excluded; group (2) 18 patients undergoing rapid weight reduction by other means (diet plus dental splintage 10; gastric reduction 8); group (3) 18 patients whose JIB was reversed for various complications.

In group (1) a characteristic arthropathy developed in 38/107 (35\%) subjects, occurred 1-78 months (mean 27 months) after operation, and was independent of pre-existing joint disease. In contrast none of the group (2) subjects developed an arthropathy. However, in group (3) 6/18 patients suffered from a similar arthropathy, which following reversal of the intestinal bypass underwent immediate complete and permanent resolution.

JIB arthropathy is a distinctive complex of articular symptoms which are dependent on the presence of an intestinal bypass but independent of osteomalacia, preexisting joint disease, and the metabolic effects of rapid weight reduction.

Polymorphonuclear leucocyte chemotaxis-the need for caution. D. Goddard, A. Kirk, D. McCarthy, ${ }^{*}$ and E. J. Holborow. Bone and Joint Research Unit, The London Hospital Medical College, London E1, and *Department of Plant Virology, Queen Mary College, London E1.

Membrane binding and internalisation of immune complexes (ICs) by polymorphonuclear leucocytes (PMNs) have been shown to result in altered function 
as measured by in-vitro tests. Despite often high levels of ICs in rheumatoid arthritis (RA) a consistent defect in PMN chemotaxis has not been found, although immunofluorescence tests have identified ICs in the cytoplasm of these cells.

Stable IgG aggregates whose biological activity resembles ICs have been used to study the changes that occur in normal PMN motility after their uptake by these cells using the micropore filter assay. The 'leading front' measurement ${ }^{1}$ as well as analysis of cell distributions through the filters have been made.

IgG aggregates were found to stimulate or inhibit PMN chemotaxis in vitro, their effect being dependent on their size as well as the length of time of incubation. Analysis of cell distributions through the filters showed that increased chemotactic responsiveness was confined to a small subset of PMNs only, and this was not obvious when only the 'leading front' measurement was made.

These results indicate that $\mathrm{IgG}$ aggregates have a complex effect on PMN motility in vitro. They also show the need for caution when interpreting results of micropore filter assays.

\section{Zigmond S, Hirsch J. J Exp Med 1973; 137: 387-410.}

Haematuria occurring during antirheumatoid therapy. E. G. White, G. C. Zaphiropoulos. Department of Rheumatology, Coventry and Warwickshire Hospital, Coventry CV1 4FH.

Compared with proteinuria the significance of haematuria occurring during treatment with antirheumatoid drugs is less clear. To help clarify this we examined details of 180 patients with 214 treatments (111 penicillamine and 103 gold), observed over a 7-year period.

Nineteen patients showed haematuria, confirmed by microscopy, unrelated to menstruation or thrombocytopenia. In 11 a cause was found as follows: urinary tract infection 8 , renal carcinoma 1 , postprostatectomy 1 , carcinoma of cervix 1 . Of the 8 patients where the cause remained in doubt a causal relationship with therapy was suspected in 5. Investigations included intravenous pyelogram in 7, cystoscopy in 5 , and renal biopsy in 1 . In 3 patients (gold) treatment was continued for a period ranging from 18 months to 5 years with no apparent deterioration in renal function, although haematuria continued to occur intermittently. In no patient was there coincidental proteinuria.

In summary, haematuria is a common finding in patients monitored during antirheumatoid therapy, occurring in some $10 \%$ of our patients. It requires investigation, as some will have serious conditions unrelated to treatment. However, where these have been excluded, and in the absence of proteinuria, haematuria does not appear to signify the presence of serious renal disease.

A multicentre study to compare the efficacy and patient acceptance of azapropazone and allopurinol in the treatment of chronic gout and/or hyperuricaemia. J. S. Templeton, Director, International Clinical Research, A. H. Robins Co., 14/15 Conduit Street, London W1R 9TG.

Azapropazone is a nonsteroidal anti-inflammatory drug (NSAID) approved for use in acute gout and the usual variety of arthropathies. Recent work $^{1}$ has shown that azapropazone is effective in suppressing urate crystal-induced rat foot pad oedema and also that it causes hypouricaemia in man.

In the study reported here investigators were asked to define a population of patients satisfactorily receiving treatment with allopurinol and alter the therapy in half such patients to azapropazone. Both groups were followed up for 6 months initially. Assessments included serum urate measurements, renal function data, incidence of acute gouty attacks, and adverse effects.

Data on $300+$ patients enrolled into the study show that: (1) serum urate levels remained well controlled in those patients switched to azapropazone; (2) more allopurinol treated patients developed acute gouty attacks; (3) renal function on azapropazone was not significantly altered; and (4) azapropazone produced in the chronic gouty patient analgesia as well as hypouricaemia. It is concluded that azapropazone is a useful drug for the long-term control of patients with chronic gout/hyperuricaemia.

1 Dieppe P A, Doherty M, Whicher J T, Walters G. Eur J Rheumatol Inflamm 1981; 4: 392.

Genetic markers in vinyl chloride disease. C. $M$. Black, A. McGreggor, R. M. Bernstein, A. E. Walker, P. J. Maddison, K. I. Welsh. West Middlesex, Hammersmith, and Guy's Hospitals, London, and the Royal Hospitals of Chesterfield and Bath.

Vinyl chloride (VC) monomer is capable of inducing a scleroderma-like syndrome in a proportion of workers who are exposed to it during polyvinyl chloride (PVC) production. This disease is unusual because (i) the actual causative agent is known; (ii) only certain of the exposed population develop symptoms; and (iii) all the exposed population can be studied for genetic markers of individuality.

As part of a 5-year follow-up study we have HLA A, B, and DR typed, complement allotyped, and 
immunoglobulin (Gm) allotyped 42 PVC production workers who had developed severe or mild VC disease.Antibodies to centromere, Scl-70, and to collagen types $\mathrm{I}$ to $\mathrm{V}$ were also assayed in patients and controls. Results were compared with those obtained on a panel of hospital workers and with those observed in 50 patients with 'classical' scleroderma.

One significant finding was that 11 of the 21 patients classified as having severe VC disease were HLA B8 and DR3 + ve. In marked contrast none of the 23 patients having mild disease carried either of these 2 antigens ( $p$ between the 2 groups $=0.0006$ ).

In general, however, the HLA antigen frequencies in the VC disease patients mirrored those found in scleroderma (e.g., raised DR5), but there were significant differences in the occurrence of autoantibodies in the 2 conditions. For example, both groups produced antibodies in differing amounts to the collagen subtypes, and no anticentromere or Scl-70 antibodies were found in the VC patients.

HLA-B27 and HLA-DR4 in definite/classical rheumatoid arthritis (RA). N. Christophidis, E. C. Huskisson, E. Wolf, A. G. Cudworth. Departments of Rheumatology and Immunologenetics. St Bartholomew's Hospital, London EC1.

The phenotype frequency of HLA B27 in our healthy control panel is $7 \%$. It is present in $23 \%$ of patients with seronegative peripheral arthritis, and of these $83 \%$ have radiological evidence of sacroiliitis. ${ }^{1}$

We report the incidental finding of HLA B27 and DR4 in definite/classical RA (ARA criteria). Seventy two $(50 \mathrm{~F}, 22 \mathrm{M})$ patients with adult-onset, progressive disease requiring treatment with penicillamine were studied. $81 \%$ were positive for IgM rheumatoid factor. The patients were typed for HLA A, B, C, antigens by a microlymphocytotoxicity test and by a 2-colour fluorescence technique for DR antigens. HLA DR4 was present in 50/67 (75\%) and HLA B27 in 11/72 (15\%). The HLA B27 positive patients comprised $8 \mathrm{~F}, 3 \mathrm{M}$, of whom 9 were positive for HLA DR4 and all for IgM rheumatoid factor.

Prior to tissue typing none were suspected of having ankylosing spondylitis. However, on further assessment 2 males had clinical and/or radiological evidence of sacroiliitis. Symptoms were only minor in 1 and absent in the other.

The higher than expected frequency of HLA B27 in our group of patients is in agreement with Cleland et al. ${ }^{2}$ who found a $14 \%$ incidence in seropositive RA. However, the lower than expected frequency of sacroiliitis and symptoms when compared with seronegative disease raises the possibility that disease expression was modified by the DR4 antigen and/or the female predominance in our patients.

1 Nasrallah N S, et al. Am J Med 1977; 63: 379-86.

2 Cleland L G, et al. Scand J Rheumatol 1975; 4: abstr 30-20.

Is radiological monitoring of drug effect in rheumatoid arthritis an unattainable goal? T. Pullar, J. A. Hunter, H. A. Capell. University Department of Medicine, Centre for Rheumatic Diseases and Gartnavel General Hospital, Glasgow.

Penicillamine (P), levamisole $(\mathrm{L})$, and intramuscular gold $(\mathrm{G})$ have all been shown to produce clinical and laboratory improvement in active rheumatoid disease. Their effect on radiological progression is, however, less clear. In this study erythrocyte sedimentation rate (ESR), haemoglobin ( $\mathrm{Hb})$, and hand radiographs at the start and after 2 years of therapy were assessed in 57 patients $(26 \mathrm{G}, 21 \mathrm{P}, 10$ L). In addition 10 control patients who had consistently refused 2 nd line treatment for at least 2 years were similarly assessed.

Age, disease duration, initial ESR, $\mathrm{Hb}$, and $x$-ray scores were similar in all 4 groups. After 2 years the ESR fell and $\mathrm{Hb}$ rose in patients on $\mathrm{G}$ and $\mathrm{P}$, but not in controls or patients treated with $\mathrm{L}$.

Hand radiograph scores by a modified Sharp method $^{1}$ showed good inter- and intraobserver agreement. Initial scores across the 4 groups were similar (Kruskal-Wallis test), as were 2-year scores. There was significant progression in all 4 groups (Wilcoxon test) with no difference between the groups. $X$-rays were also assessed by a chronological method, but this proved difficult to evaluate.

Conclusive results about subtle changes would necessitate large numbers of patients (some on placebo) over prolonged periods. This would seem an unattainable goal in current rheumatological practice.

1 Sharp J T, et al. Arthritis Rheum 1971; 14: 706-20.

HLA DR in B27 + ve and B27-ve sacro-iliitis and AS. F. Beaudet, ${ }^{*}$ B. Bissonnette, ${ }^{*}$ F. Gervais. $\dagger{ }^{*}$ Hôpital due Sacré Coeur and †Montreal- General Hospital, Montreal, Canada.

The strongest HLA/disease association known is for B27 and ankylosing spondylitis (AS). Other arthritides (e.g., RA) show both +ve and -ve associations with HLA D/DR. Studies of HLA D/DR gene frequency in AS are contradictory, and we have therefore expanded these studies to include patients 
who have sacroiliitis (SI) alone, without associated diseases, as well as patients with AS.

HLA DR typing was performed in (1) 10 B27-ve SI patients, (2) $18 \mathrm{~B} 27$ + ve patients of which 14 had AS and 4 SI alone, and (3) 18 normal matched controls. SI diagnosis was established by clinical, quantitative ${ }^{99 \mathrm{~m}} \mathrm{Tc} \mathrm{SI} / \mathrm{sacrum}$ uptake ratio and/or radiological criteria (New York classification). The AS diagnosis was established by clinical and radiological criteria.

HLA DR 1 frequency was significantly decreased in B27-ve SI patients compared with B27 AS patients $(p<0.05)$. This result can be explained by linkage disequilibrium existing between B27 and DR 1 antigen data $\left(\chi^{2}=34.4\right)$ increasing the chance of having DR 1 antigen in B27+ve AS patients. HLA DR 2 frequency was also significantly decreased in B27-ve SI patients compared with AS patients $(p<0.05)$ and controls $(p<0.05)$. HLA DR 3 frequency was decreased in AS patients compared with controls $(p<0.05)$. No significant difference was found in other DR antigens (Table 4).

Our study confirms that no single DR locus is associated with AS or SI. The significant reduction in the frequency of the immune response genes DR 1 and 2 in patients with B27-ve SI and DR 3 in AS may be of prognostic significance.

Table $4 \quad D R$ antigen frequency (\%)

\begin{tabular}{lclc}
\hline & $\begin{array}{l}\text { SI B27-ve } \\
(10)^{*}\end{array}$ & $\begin{array}{l}\text { SI/AS B27+ve } \\
(18)\end{array}$ & $\begin{array}{l}\text { Controls } \\
(18)\end{array}$ \\
\hline DR 1 & $10 \dagger$ & 44 & 28 \\
DR 2 & $0 \ddagger$ & 11 & 22 \\
DR 3 & 40 & 168 & 50 \\
DR 4 & 40 & 39 & 22 \\
DR 5 & 40 & 28 & 28 \\
DR 6 & 10 & 28 & $5 \cdot 5$ \\
DR 7 & 40 & 22 & 11 \\
DR 8 & 0 & 0 & $5 \cdot 5$ \\
DR 9 & 0 & 0 & 0 \\
DR 10 & 0 & 0 & $5 \cdot 5$ \\
\hline
\end{tabular}

*Number of patients.

†B27-ve SI vs. B27+ve SI/AS: $\chi^{2}=3.93, p<0.05$.

¥B27-ve SI (vs. B27+ve SI/AS: $t$ test, $p<0.05$.

(vs. controls: $t$ test, $p<0.05$.

$\S B 27+$ ve SI or AS vs. controls: $\chi^{2}=4 \cdot 65, p<0.05$.

Chloroquine and dapsone in the treatment of rheumatoid arthritis: a comparative study. $P$. $R$. Crook, P. D. Fowler, M. F. Shadforth. Staffordshire Rheumatology Centre, Stoke-on-Trent.

As part of a project attempting to define demographic, clinical, and laboratory features, which may give early indications of response to therapy, a group of 60 patients with active rheumatoid arthritis (RA) were randomly allocated to receive either chloroquine phosphate (CQ) $250 \mathrm{mg}$ daily or dapsone (DDS) $50 \mathrm{mg}$ daily for 1 week, then $100 \mathrm{mg}$ daily. We are reporting our results following 6 months therapy.

Following a 1-month pretreatment observation period clinical assessments were made 2 monthly, with monthly laboratory tests and 6 monthly $x$-rays. There were 6 withdrawals taking CQ, 2 due to anorexia and nausea and 4 for non-drug-related reasons. Ten DDS patients were withdrawn, 5 due to adverse effects (4 haemolysis and 1 bronchitis), 5 with lack of effect (1 also haemolysed), and 1 for other reasons.

Of those patients completing 6 months' treatment the number of painful joints, Ritchie index, pain scores, morning stiffness, ESR, and C-reactive protein showed similar significant decreases in both groups, but $x$-rays were unchanged.

Improvements were seen in both groups by 2 months. By defined criteria 8 patients taking each drug had both a clinical and laboratory improvement, and 13 CQ but only 4 DDS showed either a clinical or laboratory improvement.

Both CQ and DDS have shown suppressive effect in RA. In our study, with fewer withdrawals and more patients improving, $\mathrm{CQ}$ appears the preferable drug. We are continuing to follow these patients for up to 2 years.

${ }^{90} \mathrm{Y}$ therapy and ${ }^{99 \mathrm{~m}} \mathrm{Tc}$ uptake in rheumatoid arthritis. V. Kyle, B. Hazleman, E. P. Wraight.* Rheumatology Research Unit, Addenbrooke's Hospital, Cambridge; *Nuclear Medicine Department.

Radioactive colloids can be used to treat chronic synovitis and the effects on synovial activity objectively assessed by measuring radionuclide uptake. We treated 28 chronic knee effusions of patients with rheumatoid arthritis using intra-articular ${ }^{90}$ Yttrium, and measured ${ }^{99 \mathrm{~m}} \mathrm{Tc}$ pertechnetate uptake to assess synovial activity. There was a significant difference in ${ }^{99 m} \mathrm{Tc}$ uptake between patients and controls. Those who had a good response to ${ }^{90} \mathrm{Y}$ (15 patients) showed a significant decrease in uptake not seen in those who failed to respond.

The distribution patterns of ${ }^{90} \mathrm{Y}$ in the knee joint were studied and appeared to correspond to synovial activity. In one example ${ }^{90} \mathrm{Y}$ was repeated after 6 months because of poor response. The first scan showed an area of marked central localisation, which appeared on the second scan as a cold area surrounded by diffuse activity. These patterns have rarely been reported, and it has been suggested that ${ }^{90} \mathrm{Y}$ scans could not demonstrate variations in synovial activity. Our study suggests this is incorrect. The 
value of ${ }^{90} \mathrm{Y}$ therapy was confirmed, although none of the standard clinical or laboratory parameters could predict which patients would respond.

The effect of incorporated cholesterol sugar derivatives on the interactions of liposomes with rabbit synovial fibroblasts in vitro. J. J. Cowper, D. P. Page Thomas. Strangeways Research Laboratory, Worts Causeway, Cambridge CB1 4RN.

The incorporation of various sugar derivatives of cholesterol into liposome bylayers has been shown to alter both their stability and tissue specificity in vivo. ${ }^{1}$ We have studied the effect of similar compounds on the association of liposomes with rabbit synovial fibroblasts in vitro. Liposomes prepared with either distearoyl, dipalmitoyl, dimyristoyl, or dioeoyl phosphatidylcholine, and containing also the cholesteryl sugar and a nonexchangeable radiolabel, were added to dishes of confluent rabbit synovial fibroblasts, at a concentration of $200 \mu \mathrm{g}$ lipid per ml.

The cell association after 4 hours of distearoyl phosphatidylcholine liposomes was significantly increased by the incorporation of 5 mole \% mannose, fucose, galactose, glucose, or galactoglucose, and in particular 6-aminomannose derivatives of cholesterol (Table 5). Similarly, when cholesterol 6-aminomannose was added to dimyristoyl or dipalmitoyl lecithin liposomes, the cell association was greatly increased over that of the control liposomes. Liposomal incorporation of cholesterol 6-aminomannose offers a possible method for maintaining high liposome concentrations associated with synovial cells in joint cavities, and thus aids in the delivery of liposomally entrapped therapeutic agents in the treatment of rheumatoid arthritis.

1 Mauk M R, Gamble R C, Baldeschwieler J D.Proc Natl Acad Sci USA 1980; 77: 4430.

Table 5 Degree of association of DSPC liposomes containing 5 mole \% cholesterylthiosugars with rabbit synovial fibroblasts in vitro. Conditions: $\left[{ }^{14} \mathrm{C}\right.$-cholesteryl oleate as tracer. $200 \mu \mathrm{g}$ lipid per dish in DMEM containing $10 \% \mathrm{FCS}$. Incubated in $4 \mathrm{~h}$ at $37^{\circ} \mathrm{C}$

\begin{tabular}{lc}
\hline Sugar & $\begin{array}{l}\text { Average } \mu g \text { lipid recovered } \\
\text { per } 10^{5} \text { cells }( \pm S E M)\end{array}$ \\
\hline NAgalactose & $1 \cdot 16 \pm 0 \cdot 09$ \\
NAglucose & $1 \cdot 41 \pm 0 \cdot 18$ \\
None & $2 \cdot 23 \pm 0 \cdot 13$ \\
Gal/glu & $3 \cdot 04 \pm 0 \cdot 27$ \\
Glucose & $4 \cdot 80 \pm 0 \cdot 15$ \\
Mannose & $5 \cdot 19 \pm 0 \cdot 25$ \\
Fucose & $6 \cdot 38 \pm 0 \cdot 19$ \\
Galactose & $8 \cdot 29 \pm 0 \cdot 68$ \\
6-amino mannose & $16 \cdot 99 \pm 0 \cdot 62$ \\
\hline
\end{tabular}

Free thiomalate circulates in plasma of patients receiving sodium aurothiomalate. $S$. R. Rudge, D. Perrett, P. L. Drury, A. J. Swannell. Department of Rheumatology, City Hospital, Nottingham, and Dunn Laboratories, St Bartholomew's Hospital, London.

There is increasing evidence from animal and other studies that the - SH group may be the active component of several second-line antirheumatic agents including penicillamine and sodium aurothiomalate. ${ }^{1}$ Thiomalate, which has a free - $\mathrm{SH}$ group, has been detected in the urine of patients with rheumatoid arthritis receiving aurothiomalate. ${ }^{2}$

Using a modification of a previous method ${ }^{2}$ (highperformance liquid chromatography with electrochemical detection) we have improved the detection limit for thiomalate to $200 \mathrm{fmol}$ injected onto the column (equivalent to $10 \mathrm{nmol} / \mathrm{l}$ ). Reproducibility was $2 \cdot 1 \%(\mathrm{n}=10)$, and response was linear with increasing amounts of thiomalate injected $(r=0 \cdot 99$, $\mathrm{p}<0 \cdot 001)$.

Free thiomalate has been detected in the plasma of previously untreated patients within $30 \mathrm{~min}$ of receiving their initial injection, peak levels of 480 and 220 $\mathrm{nmol} / \mathrm{l}$ being seen at 1 hour. This is the first demon-0 stration of free circulating thiomalate in man and strengthens the case for a central role of the $-\mathrm{SH}$ ? group in the mechanism of action of aurothiomalate.

1 Jellum E, Munthe E. Scand J Rheumatol 1979; suppl 28: 28.

2 Rudge S R, Perrett D, Drury P L.Ann Rheum Dis 1982; 41: 312.

Haematuria and rheumatoid arthritis. L. D. Hordon, L. Sellars, R. Wilkinson, I. D. Griffiths, M. Thompson. Departments of Rheumatology and Nephrology, The Freeman Hospital, Freeman Road, Newcastle upon Tyne.

A series of 25 patients suffering from classical rheumatoid arthritis have been investigated for concurrent isolated haematuria as defined by repetitive detection of red blood cells in the urine, in the absence of significant proteinuria or pyuria. Both medical and surgical causes of painless haematuria were discovered. Nonrenal causes were found in only 3 patients, comprising 1 suffering from papillary urothelial carcinoma, 1 haemorrhagic cystitis, and 1 chronic cystitis. None of these patients were receiving cytotoxic agents. Among the nonsurgical cases there was a predominance of glomerular mesangial increase on renal biopsy $(n=13)$. Of this group only 3 patients had received gold or penicillamine. One patient on hydroxychloroquine was found to have a mild increase in mesangial matrix. Additionally, 9 
patients receiving nonsteroidal analgesic/antiinflammatory drugs alone had glomerular mesangial changes. None of the patients with mesangial changes have developed impairment of renal function.

It would appear from this retrospective study that glomerular lesions are the most common cause of isolated haematuria in patients suffering from rheumatoid arthritis, and these are not necessarily associated with second-line therapy.

Penicillamine nephropathy and iron. J. A. L. Harkness, D. R. Blake. Royal National Hospital for Rheumatic Diseases, Bath BA1 1RL.

The incidence of penicillamine-induced glomerulonephritis is reduced by employing a regimen of gradual dosage increments and avoiding the high levels originally recommended. Coadministration of oral iron has been shown to effectively inhibit penicillamine absorption by chelation in the gut and to influence the response of patients with rheumatoid arthritis to penicillamine therapy. Cessation of oral iron in patients stabilised on penicillamine may result in a sudden increase in absorption of the drug and associated risk of toxicity. We studied the last 20 patients at our hospital with penicillamine and nephropathy; 16 were available for review. Seven patients $(44 \%)$ were found to have been on iron therapy, 6 without the knowledge of the hospital clinician. In 4 patients (25\%) significant proteinuria developed between 2 and 5 months after stopping oral iron, and renal biopsy in 3 of these patients confirmed membranous glomerulonephritis. We believe the prevalence and hazards of simultaneous oral iron therapy in patients on pencillamine requires further emphasis.

\footnotetext{
An attempt to modify klebsiella carriage in ankylosing spondylitic patients by diet. Correlation of klebsiella carriage with disease activity. V. Neumann, R. Shinebaum, R. Hopkins, E. M. Cooke, V. Wright.

Patients with ankylosing spondylitis (AS) were asked to follow a 'klebsiella exclusion diet' for 5 months of a 10-month study. The same percentage of faecal samples were positive for klebsiella whether the patients were on or off the experimental diet. The diet also failed to influence variability of klebsiella serotypes. We found no correlation between klebsiella carriage and any of the following parameters measuring disease activity: morning stiffness, pain measured on a visual analogue scale, analgesic consumption, ESR, IgA.
}

In conclusion, we failed to alter faecal klebsiella carriage by dietary means. The data also cast doubt on whether klebsiella is involved in disease exacerbation in AS.

Forefoot arthroplasty in rheumatoid arthritis. A. Roy Taylor, S. Biswas. Stoke Mandeville Hospital, Aylesbury, Bucks.

Forefoot arthroplasty in one of its forms has now gained a place in the surgery of the rheumatoid foot. Results are, however, variable. We have analysed the results of this operation carried out in our unit between 1965 and 1981. There was a total of 125 operations, the majority of which were bilateral; $80 \%$ of the patients were female. All patients had established rheumatoid arthritis, with forefoot pain on standing or walking; about $50 \%$ had in addition toe pain and hammer deformities. Callosites under the metatarsal head were a uniform finding; $20 \%$ had to wear surgical shoes and the rest a soft wide shoe.

All operations were performed from the dorsal aspect of the foot, with preservation of soft tissues. $83 \%$ were considered to be good or excellent at follow-up. Only $6.5 \%$ considered they were worse. The majority were able to wear normal footwear. Callosities disappeared spontaneously.

The main complications were superficial infection in $13 \mathrm{feet}$, and a minor wound dehiscence in 5. The main reason for failure was recurrence of forefoot pain, the main cause of this being new bone growth at the metatarsal necks. The foot was always reduced in size.

Penicillamine failures-what can be done? M. Martin, N. Sitton, J. Dixon, P. Hickling, J. Golding, V. Wright. Clinical Pharmacology Unit, Royal Bath Hospital, Harrogate, and St James's Hospital, Leeds.

Treatment of rheumatoid arthritis (RA) with lowdose D-penicillamine (DPA) $(<500 \mathrm{mg})$ produces a favourable response in $60-70 \%$ of patients. However, despite continued treatment, an initial response often gives way to a reactivation of disease. Combination therapy with DPA and hydroxychloroquine (HCQ) has been successfully applied in an open parallel study and produced changes equal to or better than either drug given alone. No apparent drug interaction was recorded. ${ }^{1}$

In a blind study of 30 patients on low-dose DPA therapy who were considered to have active, progressive arthritis (ARA criteria), patients were randomly allocated to receive either $(a)$ an increased 
dose of DPA, or $(b)$ combination treatment with the addition of HCQ. Their progress was monitored clinically and biochemically over a period of 6 months.

The results in both groups were similar. Approximately $50 \%$ reported a good clinical response with either treatment. Significant improvements were recorded in articular index, pain score, ESR, viscosity, and CRP and there was no statistical difference between the 2 treatment groups.

This study suggests that in clinical practice patients failing to respond to DPA could be considered either for higher dose DPA therapy or be given combination treatment with DPA and HCQ.

1 Martin M, et al. Ann Rheum Dis 1982; 41: 208.

Penicillamine-induced myasthenia in rheumatoid arthritis: its clinical and genetic features. J. P. Delamere, ${ }^{*}$ S. Jobson, $\dagger$ L. P. Mackintosh, $\dagger$ L. Wells, $\dagger$ K. W. Walton. ${ }^{*}$ Department of Investigative Pathology, The Medical School, Birmingham University, and $\nmid$ Regional Blood Transfusion Service, Birmingham.

Pencillamine-induced myasthenia (PIM) closely resembles spontaneous-onset myasthenia gravis both clinically, humorally, and in its association with thymic hyperplasia. A genetic predisposition to the development of spontaneous-onset myasthenia gravis, when associated with thymic hyperplasia, has been inferred from the increased incidence of the HLA antigens B8 and Dr3. We have investigated the possibility that a genetic factor might influence the development and/or expression of PIM.

The clinical features, HLA type, and the alleles of the complement components $\mathrm{C} 2, \mathrm{C} 4$, and factor B were ascertained in 18 rheumatoid patients who had developed PIM. The initial myasthenic symptoms consisted in all subjects of variable diplopia and/or ptosis with progression to a more generalised involvement occurring in 7 subjects. No clinical, humoral, or genetic factor was determined which would allow identification of individuals developing generalised as opposed to occular myasthenia.

The PIM subjects, when compared with a healthy control population, had a significant increase in HLA Dr 1 (P corr $<0.005)$, a normal distribution of HLA B8 (28\%), but an absence of HLA Dr 3. Typing of complement factor $B$ added further support for a disruption in these subjects of the normal HLA B8 allelic associations. A genetic susceptibility to the development of PIM, distinct from that observed in spontaneous-onset myasthenia gravis, is strongly suggested by this distribution of HLA Dr antigens.
Superoxide anion $\left(\mathrm{O}_{2}^{-}\right)$generation by blood monocytes (Mø): stimulant effect of gold and penicillamine during treatment of RA patients. N. P. Hurst, B. Bessac, G. Nuki. Rheumatic Diseases Unit (WGH), University of Edinburgh.

The contributin of phagocyte-derived $\mathrm{O}_{2}^{-}$-free radicals to inflammation is now well recognised. Since mononuclear phagocytes are thought to play an important role in RA we have studied $\mathrm{O}_{2}^{-}$generation by $\mathrm{M} \varnothing$ from RA patients. We have previously reported that $\mathrm{M} \varnothing$ from RA patients on 2nd-line therapy showed greater release of $\mathrm{O}_{2}^{-}$after immunological stimulation than Mø from normal controls or RA patients on 1st-line drugs. No differences were found using a nonimmunological stimulus (fluoride ${ }^{\top}$ ).

To determine whether this phenomenon was related to therapy or disease activity we have studied 14 RA patients (classical/definite) before and after therapy with gold $(n=7)$ or penicillamine $(n=7)$ and a further 18 normal controls. Rates of $\mathrm{O}_{2}^{-}$release by Mø after stimulation with serum treated (STZ) or IgG treated (IgGTZ) zymozan were measured by reduction of cytochrome $C$ as previously described. ${ }^{1}$ Studies were performed before and at 3 and 6 months after treatment.

Mean ESR in patients who responded (R) to treatment fell significantly but was unchanged in nonresponders (Fig. 1). Before therapy, responders (R) had significantly lower rates of $\mathrm{O}_{2}$ release after STZ $(p<0.05)$ or IgGTZ $(p<0.02)$ stimulation than nonresponders (NR), Fig. 1). After 3 and 6 months therapy $\mathrm{O}_{2}$ release by $\mathrm{M} \varnothing$ from responders increased significantly and paradoxically to the elevated levels seen in nonresponders (Fig. 1). These data demonstrate that $(a)$ gold and penicillamine directly or indirectly enhance the capacity of $\mathrm{M} \varnothing$ to generate $\mathrm{O}_{2}$-free radicals in response to immune stimuli; $(b)$ a biological difference exists between responders and nonresponders to gold and penicillamine; $(c)$ the capacity of $\mathrm{M} \varnothing$ to generate $\mathrm{O}_{2}$-free radicals is not linked directly with disease activity in RA.

1 Weening R S, Wever R, Roos D. J. Lab Clin Med 1975; 85:
242-52.

The effect of antirheumatic drugs on the phagocytic activity of synovial macrophages in organ culture. $J$. D. Jessop, M. Wilkins, M. H. Young, Department of Rheumatology, University Hospital of Wales, Cardiff CF4 4XW.

The phagocytic activity of human synovial macrophages has been assessed using yeast coated glass coverslips on synovial explants maintained in organ culture for 24 hours. Synovium was excised from the 

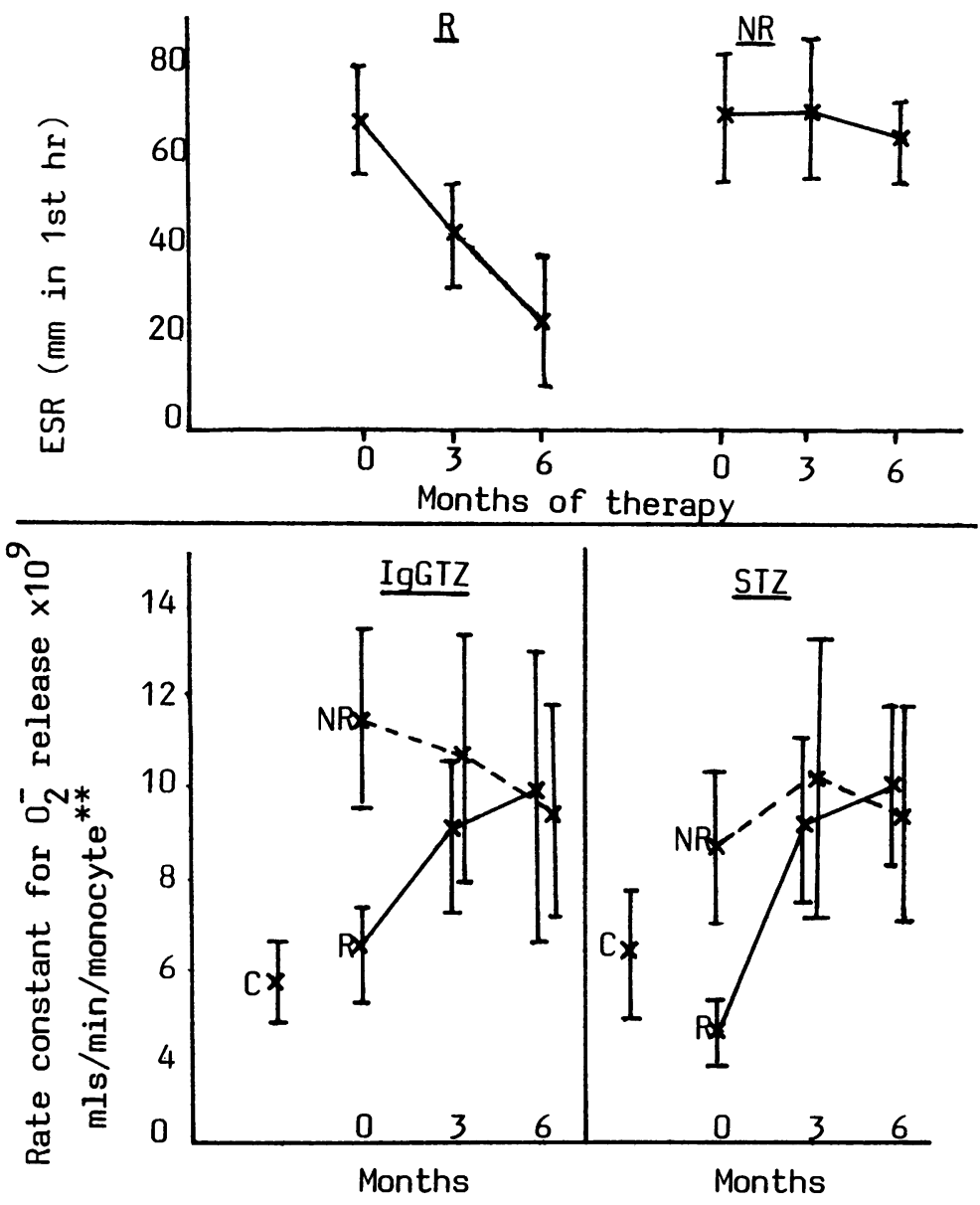

Fig. $1 \mathrm{C}=$ Normal controls.

$$
\begin{aligned}
& \mathrm{R}=\text { Responders to } 2 \mathrm{nd}-\text { line therapy }(\mathrm{n}=9) \times-\times \\
& \mathrm{NR}=\text { Nonresponders to } 2 \mathrm{nd}-\mathrm{line} \text { therapy }(\mathrm{n}=5) \times--\times . \\
& { }^{* *} \text { Rate const. }=\operatorname{In}\left[\frac{\mathrm{CytC} \mathrm{Ox}}{\mathrm{CytC}^{\mathrm{t}} \mathrm{ox}}\right] \times \frac{1}{\text { time } \times[\mathrm{M} \emptyset]} \mathrm{ml} / \mathrm{min} / \mathrm{M} \emptyset .
\end{aligned}
$$

knee joints of 28 patients with rheumatoid arthritis (RA), 7 with osteoarthritis (OA), and 23 menisectomy 'normals'. Antirheumatic drugs were added to the culture medium to observe the effect on phagocytosis.

Results (mean \%) showed a significantly higher phagocytic activity in RA $(67 \cdot 5 \%)$ compared with normals $(39 \%)(p<0.001)$ and in OA $(55 \%)$ compared with normals $(p<0 \cdot 001)$. In RA there was significant suppression of phagocytosis by hydrocortisone $10^{-3} \mathrm{mmol} / 1(47 \% \mathrm{p}<0 \cdot 001)$, aurothioglucose $3 \mathrm{mg} / \mathrm{ml}(39 \% \mathrm{p}<0.001)$, D-penicillamine $10 \mathrm{mg} / \mathrm{ml}$
$(37 \% \mathrm{p}<0.001)$, and auranofin $10 \mathrm{mg} / \mathrm{ml}(26 \%$ $\mathrm{p}<0.001)$. There was no significant suppression by aspirin or levamisole. In normal synovium phagocytic activity was unaffected by all drugs except levamisole, which increased phagocytosis (66\%, $\mathrm{p}<0.001$ ). With acid phosphatase and leucine naphthylamidase histochemical reactions cell membranes from normal synovium were significantly more stable than rheumatoid $(p<0.001)$. In culture there was a significant effect on the stabilisation of the membrane in RA by hydrocortisone $(p<0.02)$ and by aurothioglucose $(p<0 \cdot 005)$. Analysis of a number of 
histological parameters demonstrated a positive correlation between a high phagocytic score $>60 \%$, surface fibrin, lymphocytes, and plasma cells.

These results suggest that organ culture is a useful model for the study of macrophage function.

A controlled trial of sulphasalazine in rheumatoid arthritis. V. Neumann, ${ }^{*}$ K. Grindulis, $\dagger$ B. McConkey, $\dagger$ H. Bird, ${ }^{*}$ V. Wright. ${ }^{*}$ Rheumatism Research Unit, Leeds, and the †Department of Rheumatology, Dudley Road Hospital, Birmingham.

Previous 'open' trials have found sulphasalazine to have a disease modifying effect in rheumatoid arthritis (RA). ${ }^{12}$ We now report on the results of a double-blind controlled trial comparing enteric coated sulphasalazine (SAS) with D-penicillamine (DPA) in patients with active RA. A total of 63 patients were recruited in 2 centres; 31 were treated with SAS and 32 received DPA. After 16 weeks' treatment both drugs had produced significant improvements in clinical score, pain score measured on a visual analogue scale, grip strength, Ritchie articular index, ESR, and serum C-reactive protein.

Nausea was the major side effect observed in the SAS-treated group. We did not encounter any potentially dangerous effects such as thrombocytopenia in this group-in contrast with the DPA-treated group.

We conclude that SAS is an effective and safe drug capable of producing remissions in active RA.

1 McConkey B, Amos R S, Durham S, Forster P J G, Hubball S, Walsh L. Br Med J 1980; i: 442.

2 Bird H A, Dixon J S, Pickup M E et al. 1982; 9: 36.

Judging 'current disease activity' in rheumatoid arthritis (RA). J. R. Kirwan, D. M. Chaput de Saintonge, C. R. B. Joyce, ${ }^{*}$ H. L. F. Currey. The London Hospital Medical College and ${ }^{*}$ Ciba-Geigy Ltd, Basle.

Clinicians differ in the importance they attach to measures of disease activity in RA but stated opinions may not reflect actual practice when making decisions about real patients. Judgments made on 'paper patients' correlate highly with those made on equivalent real patients and provide a suitable system for the analysis of real decisions.

Two rheumatologists judged 'current disease activity' in real and paper patients with RA. Analysis of each set of judgments provides a model of judgment policy which contains only 3 clinical variables but explains over $94 \%$ of the variance in judgments. The judgment policy models differ markedly from each other and from the clinicians' own perceptions of their behaviour.
Judgment policy modelling offers a means of improving co-ordination between clinical investigators within and between centres by identifying and making explicit underlying differences in clinical practice, making possible rational discussion of their importance and implications.

Seat belt legislation: do patients with arthritis need exemption? E. Arie, F. Baron, D. H. Bossingham, A. J. Swannell. City Hospital, Nottingham.

Legislation concerning the compulsory use of seat belts is expected to be enforced by the end of the year. ${ }^{1}$ Guidelines for issuing exemption certificates provided by the Medical Commission on Accident Prevention $^{2}$ anticipate few problems for arthritic patients.

Five hundred and sixty-one consecutive patients attending rheumatology clinics in Nottingham completed a questionnaire on their use of car seat belts (Table 6). Half were regular seat belt users. Onethird of this group had to overcome some difficulty due to their arthritis. Among those not using seat belts 33 car drivers and 53 passengers related their difficulty to their arthritis. Sixty-five passengers were unable to get into the back seat of a car. Aspects of joint disease contributing to these problems are analysed.

We conclude that $5 \%$ of these patients may need exemption from compulsory seat belt wearing and do not qualify on present recommendations. Modified criteria for exemption are suggested.

1 Transport Act, 1981, Section 33.

2 Medical Commission on Accident Prevention. Medical aspects of exemption from seat belt wearing: guidelines for practitioners. February, 1982.

Synovial enzyme/inhibitor ratios in erosive and nonerosive arthropathies. M. H. Pritchard. University Hospital of Wales, Cardiff.

It is not clear why some chronic arthropathies are erosive (i.e., rheumatoid arthritis (RA)) while others are not (i.e., spondyloarthropathies). To investigate any relevant differences between erosive and nonerosive joint fluids the following study has been carried out. Synovial fluid was aspirated from the knees of 106 patients: 49 RA taking antiinflammatory analgesics (NSAIDs) only, 27 RA patients taking gold or penicillamine, 22 spondyloarthropathies and reactive arthropathies, 6 septic arthritis. In all fluids the total protein, white cell count, and $\mathrm{CH} 50$ was measured together with the $\beta$ 
Table 6 Seat belt legislation-analysis of 518 questionnaires

\begin{tabular}{llllll}
\hline & \multicolumn{2}{l}{ Seat belt users } & & \multicolumn{2}{l}{ Seat belt non-users } \\
\cline { 2 - 4 } & $\begin{array}{l}\text { Drivers } \\
118(23 \%)\end{array}$ & $\begin{array}{l}\text { Passengers } \\
155(30 \%)\end{array}$ & & $\begin{array}{l}\text { Drivers } \\
99(19 \%)\end{array}$ & $\begin{array}{c}\text { Passengers } \\
146(28 \%)\end{array}$ \\
\hline $\begin{array}{l}\text { Number with no practical problems } \\
\text { with seat belt }\end{array}$ & $100(19 \%)$ & $127(25 \%)$ & $76(15 \%)$ & $116(22 \%)$ \\
$\begin{array}{l}\text { Number with difficulties with seat } \\
\text { belt due to their arthritis }\end{array}$ & $18(3 \%)$ & $57(11 \%)$ & $33(6 \%)$ & $53(10 \%)$ \\
$\begin{array}{l}\text { Number with trouble getting in or } \\
\text { out of front seat of car }\end{array}$ & 9 & $46(8 \%)$ & 2 & $43(8 \%)$ \\
$\begin{array}{c}\text { Number unable to get in or out of } \\
\text { rear seat of car }\end{array}$ & - & $62(12 \%)$ & - & $65(13 \%)$ \\
\hline
\end{tabular}

561 Patients completed the questionnaire. 204 Males (31\%). 357 Females (69\%). Rheumatoid arthritis 323 (62\%). Osteoarthritis 56 (11\%). Other diagnosis $139(27 \%) .23$ Patients never travel by car. 20 questionnaires incomplete.

glucuronidase $\left(\beta_{1} g\right)$ to estimate polymorph neutral protease secretion, and $\alpha_{1}$ antitrypsin $\left(\alpha_{1} \mathrm{AT}\right)$ and $\alpha_{2}$ macroglobulin $\left(\alpha_{2} M G\right)$ to estimate the inhibitor response. In a further 37 synovial fluids $\alpha_{1}$ IAT was correlated with C-Reactive Protein (CRP).

Table 7 shows that the range of inflammatory response, as measured by white cell count, $\alpha_{1} \mathrm{AT}$, and $\alpha_{2} \mathrm{MG}$, is the same in all 4 groups, although $\alpha_{2} \mathrm{MG}$ is surprisingly low in the RA groups. Major differences were seen in $\mathrm{CH} 50$ and $\beta_{1}$ g. The differences in the levels seen in the 3 main groups can presumably be explained by the presence of complement fixing complexes which also stimulate the polymorph enzyme secretion. This is over 3 times higher in the RA (NSAID) group than the spondyloarthritic one, with the RA gold/penicillamine results intermediate. The ratio between $\beta_{1} \mathrm{~g}$ and $\alpha_{1} \mathrm{AT}$ has been calculated for all synovial fluid and this ratio is widely different in the groups measured.
The conclusion is that enzyme production and inflammatory response in the joint are entirely independent functions, a high enzyme/inhibitor ratio being associated with erosive disease and modified by the action of gold and penicillamine.

Intravenous iron therapy for rheumatoid anaemia revisited. D. R. Blake, ${ }^{*}$ M. Ahern, $\dagger$ F. Ring, $\dagger$ J. Bradfield, $\dagger$ P. A. Bacon.* Rheumatology Research Wing, Birmingham, and †RNHRD, Bath.

Parenteral iron is claimed to improve the anaemia of RA. However, intravenous iron dextran may aggravate synovitis possibly due to RE cell blockade with subsequent immune complex synovitis.

We have infused $1 \mathrm{~g}$ of iron dextran into 12 anaemic RA patients to (re)-examine (1) the

Table 7 Synovial fluid parameters (mean $\pm S D$ )

\begin{tabular}{|c|c|c|c|c|}
\hline & $\begin{array}{l}\text { Spondylo- } \\
\text { arthropathy }\end{array}$ & $\begin{array}{l}R A \\
\text { gold/pen. }\end{array}$ & $\begin{array}{l}R A \\
N S A I D\end{array}$ & Septic \\
\hline Number & 22 & 27 & 49 & 6 \\
\hline WCC $\times 1000$ & $17 \pm 11$ & $15 \cdot 6 \pm 5 \cdot 9$ & $12 \cdot 6 \pm 6 \cdot 3$ & $122 \pm 76$ \\
\hline $\begin{array}{l}\alpha_{1} \mathrm{AT} \\
\alpha_{2} \mathrm{MG} \\
\text { Pooled normal } \\
\text { serum }=100\end{array}$ & $\begin{array}{r}109 \pm 27 \\
61 \pm 29\end{array}$ & $\begin{array}{r}115 \pm 35 \\
45 \pm 21\end{array}$ & $\begin{array}{r}121 \pm 40 \\
49 \pm 18\end{array}$ & $\begin{array}{r}116 \pm 25 \\
39 \pm 12\end{array}$ \\
\hline $\begin{array}{l}\text { CH } 50 \\
\quad \text { (Serum 28-32) }\end{array}$ & $19 \cdot 3 \pm 4 \cdot 8^{*}$ & $13 \cdot 0 \pm 8$ & $8 \cdot 9 \pm 2 \cdot 8^{*}$ & - \\
\hline $\begin{array}{l}\beta_{1} g \\
\quad \text { (Sigma units) }\end{array}$ & $20 \cdot 7 \pm 5 \cdot 9^{*}$ & $40 \cdot 4 \pm 24^{*}$ & $57 \pm 36^{*}$ & $606 \pm 763$ \\
\hline$\beta_{1} g / \alpha_{1} A T$ & $0 \cdot 20 \pm 0.05^{*}$ & $0 \cdot 39 \pm 29^{*}$ & $0.52 \pm 33^{*}$ & 6 \\
\hline
\end{tabular}

*Significant differences $p<0.05$. 
haematological response, (2) the factors that influence the response, (3) the incidence, features, and mechanism of the synovial flare.

Two patients had an anaphylactic reaction (at 20 and $75 \mathrm{~min}$ ). Of the remaining 10 patients only 2 showed a sustained $\mathrm{Hb}$ rise $(\geqslant 1 \cdot 5 \mathrm{~g} / \mathrm{l})$. Both had mild disease and a low serum ferritin $(<15 \mu \mathrm{g} / \mathrm{l})$. All 10 showed a marked increase in serum ferritin, levels peaking at 7-9 days post infusion (a pattern similar to those with pure iron deficiency). However, this did not result in any haematological response in patients with moderate/severe disease activity even if the preinf usion ferritin levels were low. Subsequent control of disease activity allowed such a response.

Nine of the 10 patients developed a synovial flare despite $48 \mathrm{~h}$ strict bed rest. The reaction was quantified and followed by infrared thermographic imaging. It peaked $24 / 48 \mathrm{~h}$ post infusion, settled in 7 days, and affected mildly inflamed small joints maximally. Immune complexes (by 3 assays) were unchanged. In a mouse model iron dextran failed to induce RE blockade measured by hepatic/splenic clearance of intravenous sheep RB cells.

Intravenous iron dextran is (1) dangerous, (2) ineffective in moderate/active RA, and (3) exacerbates inflammation in $90 \%$ of cases. This does not relate to RE blockade.

Serial quantitative sacroiliac scintiscanning: a sensitive and objective method of assessing the efficacy of nonsteroidal analgesic anti-inflammatory drugs. $\mathrm{N}$. A. Dunn, B. Mahida, M. V. Merrick, G. Nuki. Rheumatic Diseases Unit, Department of Medicine, University of Edinburgh.

Isotope scanning and other objective clinical methods of measurement have proved too insensitive to distinguish differences between nonsteroidal antiinflammatory drugs (NSAID). Quantitative sacroiliac scintigraphy (QSS) is influenced by NSAID ${ }^{1}$ although its diagnostic value in sacroiliitis remains controversial. We have used serial computer assisted QSS (Si joint/sacrum ratio)3 hours after low dosage (5mCi) ${ }^{99 m} \mathrm{Tc}$ methylene diphosphonate to assess the effects of azapropazone $600 \mathrm{mg}$ b.d. and naproxen $500 \mathrm{mg}$ b.d. in a double-blind cross-over comparison of 18 patients with active sacroiliitis. Clinical assessments included visual analogue scales for measurement of pain and early morning stiffness, chest expansion, a modified Schober test, and goniometric measurement of thoracolumbar spinal flexion using an inclinometer. Following a 7-day drug free wash out period, patients were randomly allocated to 2 therapy groups, subsequently shown to be comparable for all clinical and laboratory parameters. Assessments were undertaken before and after 14 days' drug treatment, after a further 7-day washout period, and after 14 days' therapy with the alternative NSAID.

Statistically significant decreases in pain $(\mathrm{p}<0.001)$ and early morning stiffness $(\mathrm{p}<0.001)$ followed treatment with each NSAID. No significant differences were observed in chest expansion, spinal flexion, or between drugs. Serial QSS showed that the SI/S ratio only fell significantly following treatment with naproxen $(p<0.02)$ and 16 patients preferred it at the end of the study. Thus, serial QSS can be used as an objective method of assessing sacroiliitis and is sufficiently sensitive to reflect subjective patients preference.

1 Namey T C, et al. Arthritis Rheum 1977; 20: 1058-64.

Abnormal liver scans in PMR/GCA. V. Kyle, J. Jones, B. Hazleman. Rheumatology Research Unit, Addenbrooke's Hospital, Cambridge CB2 2QQ.

Abnormalities of liver function in polymyalgia rheumatica/giant cell arteritis (PMR/GCA) are well recognised but the pathogenesis of these changes is unclear. Although histological studies have been carried out there are few descriptions of radionuclide scanning in PMR/GCA.

We report the scan findings in 6 patients with PMR/GCA, where scanning was carried out in the course of investigation of abnormal liver function tests.

All six had abnormal liver scans. Hepatomegaly was present in all cases, 5 showed patchy tracer uptake, and focal defects were noted in 3. Biopsies performed in 4 cases were normal in 2 and showed minor nonspecific changes in 2 . No other cause was found for the liver function abnormalities, which returned to normal in all cases after treatment with prednisolone.

It is clearly important to realise that PMR/GCA may cause liver scan abnormalities. Findings may otherwise be wrongly attributed to metastatic disease, especially when PMR/GCA presents with nonspecific constitutional symptoms, or additional pathology may be suspected. This can lead to further unnecessary investigations, and more importantly, corticosteroid therapy may be delayed.

The pathogenesis of the liver scan changes will also be discussed. Possible mechanisms include hepatic arteritis or parenchymal inflammation distorting blood flow. 
Scanning electron microscopy of rheumatoid arthritis polymorphonuclear leucocytes. D. A. McCarthy, J. D. Perry, ${ }^{*}$ D. H. Goddard, ${ }^{*}$ C. M. Holburn, S. R. Moore, B. K. Pell, E. J. Holborow.* Queen Mary College and *The London Hospital, London E1.

The electrophoretic mobility of blood polymorphonuclear leucocytes (PMNs) from rheumatoid arthritis (RA) patients differs from that of normal subjects, ${ }^{1}$ suggesting that the outermost membrane of the RA cells may be altered. Using conventional procedures $^{2}$ we have examined by scanning electron microscopy PMNs isolated from heparinised blood and synovial fluids. Normal PMNs were morphologically homogeneous, spherical, and randomly covered with small ridges and short ruffles, as described previously. ${ }^{2}$ In contrast RA PMNs were morphologically heterogeneous; although some cells resembled normal PMNs, others were nonspherical and had alterations to their surface membrane such as blebs, large ruffles, and bare patches. In this preliminary study it seemed that the extent of such abnormalities might be correlated with the severity of the disease. Some of the alterations seen resembled those which happen after ingestion of large numbers of bacteria in vitro ${ }^{3}$ or on prolonged incubation in autologous serum. ${ }^{2}$ Therefore the changes may be rather nonspecific, perhaps related to the phagocytosis of circulating immune complexes.

1 Howe G B, Fordham J N, Brown K A, Currey H L F. Ann Rheum Dis 1981; 40: 370.

2 Newell D G. In: Hodges G M, Hallowes R C, eds. Biomedical Res Applic of SEM. 1980; 2: 219.

3 MacRae E K, Pryzwansky K B, Cooney M H, Spitznagel J K. Cell Tissue Res 1980; 209: 65.

Measurement of IgM, IgA, and IgG rheumatoid factors by ELISA and comparison with other methods. J. Bampton, J. Park, V. Kyle, T. Cawston, B. Hazleman. Rheumatology Research Unit, Addenbrooke's Hospital, Cambridge CB2 2QQ.

An enzyme-linked immunosorbent assay (ELISA) has been developed to measure, $\operatorname{IgM}, \operatorname{IgA}$, and $\mathrm{IgG}$ rheumatoid factors (RF) in sera from 20 clinically definite rheumatoid patients and 20 normal volunteers. For comparison IgM RF was measured using conventional Rose-Waaler and latex agglutination techniques and also by rate nephelometry using a Beckman immunochemistry system. The levels of IgM RF from all assays except Rose-Waaler correlated well.

IgA and IgG RF were both significantly raised in the rheumatoid sera compared with the normal sera.
Reduction of the sera did not significantly lower the titres of IgG RF in rheumatoid sera. The ELISA could thus usefully distinguish between the different classes of RF. Some recent reports suggest that levels of IgG RF correlate with disease activity.

For routine measurement of IgM RF the rate nephelometer was the quickest and simplest method and conveniently gave the results in international units, although ELISA was more sensitive, detecting all of the clinically active rheumatoids.

Retention and intra-articular distribution of a radionuclide complexed with a liposomal hydrophobic chelator. D. R. Bard, C. G. Knight, D. P. Page-Thomas. Strangeways Research Laboratory, Worts Causeway, Cambridge CB1 4RN.

The use of radionuclides to destroy proliferative inflammatory synovium has 2 severe drawbacks. Firstly, radioactivity, even in colloidal form, escapes from the joint, and, secondly, other tissues such as cartilage and tendon may be damaged. Liposomes offer a potential solution to both these problems by immobilising the radionuclide in particles which are too large to diffuse from the joint and are likely to be accumulated by the phagocytic cells of the synovium. Water-soluble isotopes in lipsomes are, however, highly dependent for their retention on the integrity of the lipid bilayer. We have therefore synthesised a lipid-soluble chelator which is well retained by liposomes and is capable of complexing a wide variety of radionuclides.

When distearoylphosphatidylcholine liposomes containing chelator complexed with the $\gamma$ emitter ${ }^{51} \mathrm{Cr}^{3+}$ were injected into the synovial cavities of the knees of rabbits, which had been unilaterally induced with experimental arthritis, $80 \%$ of the initial activity could be detected in both joints after 4 days, whereas free ${ }^{51} \mathrm{Cr}^{3+}$ or ${ }^{51} \mathrm{Cr}^{3+}$ complexed with a water-soluble chelator fell to less than $5 \%$ of the initial activity over the same period (Table 8). Counting of the various joint tissues after necropsy revealed that over $82 \%$ of the recoverable activity from both normal and induced knees treated with liposomes had become

Table 8 Retention of radioactivity by rabbit knees (\% of initial activity, means of 3 results)

\begin{tabular}{llcc}
\hline & & 1 Day & $* 4$ Days \\
\hline Chelator & Normal & $95 \cdot 8$ & $79 \cdot 8$ \\
Liposomes & Arthritic & $99 \cdot 7$ & $80 \cdot 0$ \\
Free ${ }^{51} \mathrm{Cr}^{3+}$ & Normal & $13 \cdot 1$ & $5 \cdot 9$ \\
& Arthritic & $8 \cdot 5$ & $5 \cdot 3$ \\
\hline
\end{tabular}

*Single result. 
associated with the synovium after 24 hours (Table 9). The results show that a radionuclide bound to a lipophilic chelator in liposomes is well retained by the joint, and that radioactivity delivered in this form becomes predominantly associated with the synovium.

Table 9 Distribution of radioactivity one day after injection of chelator liposomes into rabbit knees (\% of recoverable activity, means of 3 results)

\begin{tabular}{lcc}
\hline & Normal & Arthritic \\
\hline Tendon & $8 \cdot 0$ & $3 \cdot 5$ \\
Meniscus & $8 \cdot 5$ & $2 \cdot 1$ \\
Synovium & $82 \cdot 5$ & $92 \cdot 8$ \\
Articular cartilage & $0 \cdot 8$ & $0 \cdot 3$ \\
\hline
\end{tabular}

Heberden's nodes: osteoarthritis (OA) or rheumatoid arthritis (RA)? G. Campion, P. Dieppe, I. Watt. Departments of Medicine and Radiodiagnosis, Bristol Royal Infirmary, Bristol BS2 8HW.

Firm swellings of the distal interphalangeal (DIP) joints (Heberden's nodes) are considered characteristic of OA, although DIP involvement may occur in RA and other rheumatic diseases. Since no controlled clinical and radiological data are available a study was conducted to assess the incidence and nature of DIP disease in OA and RA.

One-hundred consecutive outpatients with classical or definite RA were compared with 40 patients with interphalangeal $\mathrm{OA}$ and 42 age-sex matched controls. Clinical interphalangeal joint involvement was scored $0-3$ by one of 2 observers, and hand radiographs were graded by a radiologist unaware of the clinical diagnosis.

Clinical involvement of the DIPs was seen in $41 \%$ of the control group, $77 \%$ of those with RA, and $92 \%$ of the OA patients. Severe (grade 2 or 3 ) changes occurred in $5 \%, 12 \%$, and $24 \%$ respectively. The changes were similar in each group.

Radiological changes consistent with $O A$ were common in all 3 groups (OA $>$ RA $>$ control group). Inflammatory features were not seen in the controls and were confined to soft-tissue swelling in OA (86\%). Soft-tissue swelling was seen in $76 \%$ of RA patients, juxta-articular osteoporosis in $33 \%$, and 13 had ill-defined DIP erosions.

It is concluded that DIP joint involvement is common in RA. It is frequently clinically and radiologically indistinguishable from that of OA. However, radiological features of $R A$, including the occurrence of ill-defined erosions, are not uncommon. Heberden's nodes are not, therefore, synonymous with OA.
Rheumatoid arthritis and crystal arthropathy. J. R. Kirwan, P. G. Davies, J. N. Fordham. The London Hospital and Medical College, London E1.

Two patients with seropositive rheumatoid arthritis (RA) developed active synovitis of the knees associated with the presence of calcium pyrophosphate dihydrate (CPPD) crystals. The synovitis appeared to be related to the presence of CPPD in one patient with longstanding but currently quiescent RA. Abundant CPPD crystals were found in both knees, and synovial histology showed focal deposits of calcific material containing crystals of CPPD and changes of RA. Knee radiographs showed no evidence of chondrocalcinosis. The second patient had a general flare of RA of more recent onset. Crystals were present in synovial fluid from one knee, which showed radiographic chondrocalcinosis. A meniscectomy had been performed 48 years previously in that knee.

The presence of CPPD crystals in RA may be underestimated both clinically and radiographically (as chondrocalcinosis). These patients lend support to the thoery ${ }^{1}$ suggesting a multifactorial origin for pyrophosphate deposition disease in damaged joints.

1 Doherty M, Watt I, Dieppe P A. Lancet 1982; i: 1207.

B-lymphocyte subpopulation which forms rosettes with mouse erythrocytes increased in rheumatoid arthritis. G. R. W. Room, C. Plater-Zyberk, M. Clarke, R. N. Maini. Kennedy Institute of Rheumatology, 6 Bute Gardens, London W6 7DW.

The peripheral blood lymphocytes of 22 patients with rheumatoid arthritis (RA) were studied for the presence of a subpopulation of cells which form spontaneous rosettes with mouse erythrocytes. In normal subjects these cells have been characterised as immature B cells which are nonresponsive to pokeweed mitogen.

The mean percentage of mouse rosette-forming cells (MRFC) in the RA group was $13 \pm 10$ (mean $\pm 2 \mathrm{SD}$ ), a significantly higher value than the control mean of $5 \pm 4 \%(p<0 \cdot 001)$. The $T$ and $B$ cell percentages in the RA patients were normal. The ratio of MRFC: $B$ cells derived from these results was $3: 4$ in RA and 1:4 in normal subjects. Preincubation of rheumatoid peripheral blood lymphocytes at $4^{\circ} \mathrm{C}$ gave higher values of MRFC $(19 \pm 10 \%)$ than preincubation at $37^{\circ} \mathrm{C}(\mathrm{p}<0.02)$, but no such effect of temperature was found in the control group. There was no correlation between MRFC and disease activity or the RA patients' drug regimens. 
This 3-fold increase in mean MRFC in patients with RA adds to the cellular abnormalities described in the circulating lymphocyte pool.

Spontaneous rupture of the spleen in rheumatoid arthritis (RA). D. O. Haskard, C. S. Higgens, L. N. Temple, H. L. F. Currey. The London Hospital, London E1 1BB.

We report 2 cases of RA in whom spontaneous rupture of the spleen occurred. In neither had there been adequate trauma to explain the rupture and in both the splenic parenchyma was normal.

. In both cases the appearance of the splenic capsule was similar to that previously described in a case of RA. ${ }^{1}$ There was thickening of the capsule by dense fibrous tissue, on the surface of which was granulation tissue composed of palisades of fibroblasts, polymorphonuclear neutrophils, foamy histiocytes, and multinucleate cells. In one case bilateral pleural effusions were present. Pleural biopsy revealed a histological appearance similar to the splenic capsule. This appearance probably represents a non-organspecific histological feature of RA which occurs in serosal surfaces as well as in nodules and synovial tissue. ${ }^{12}$

We conclude that splenic capsular involvement may predispose to splenic rupture in a manner comparable to the rupture of rheumatoid pleural nodules, which leads to a sterile pyopneumothorax. We are not aware of spontaneous splenic rupture having previously been described in association with RA.

1 Gruenwald P. Arch Pathol 1948; $46: 59$.

2 Champion G D, Robertson M R, Robinson R G. Ann Rheum Dis 1968; 27: 521.

Beer and its effect on uric acid. T. Gibson, A. V. Rodgers, H. A. Simmonds, P. Toseland. Guy's Hospital, London SE1.

The association between hyperuricaemia and alcohol is well established. The mechanism is presumed to be mediated by serum lactate, which impairs urate excretion. This has been shown by intake of alcohol in excess of that usually drunk by our gout patients. Such studies have been conducted fasting, making it difficult to dissociate this influence from that of lactate on urate clearance. Our typical gout patients drink beer with a normal diet. The current study assessed the effect of alcohol on urate by simulating their drinking habits.

Five patients with gout and 5 controls ate a constant purine diet for 5 days. On 2 days they drank $2 \cdot 8$ litres of beer containing $1 \cdot 1 \mathrm{mmol}$ purines and $54 \mathrm{~g}$ ethanol. During the other 3 days equivalent volumes of diluted squash were consumed. Beer and squash increased serum lactate. Beer caused a marked decline of urine $\mathrm{pH}$. Plasma urate increased by $11-12 \%$ in both groups with beer, but not with squash. Urine uric acid increased with beer by $15 \%$ in the gouty and $20 \%$ in controls. Excretion of other oxypurines did not alter. Urate clearance increased several fold during the periods when squash and beer were drunk. Clearance values were consistently higher in the controls.

Thus, despite a fall of urine $\mathrm{pH}$ and rise of serum lactate, beer accentuated urate clearance. The rise of uric acid excretion could represent an increase of endogenous uric acid synthesis, absorption of purines, or both. There was no evidence that impaired urate clearance contributed to the increase of plasma urate.

Impairment of higher cerebral function in systemic lupus erythematosus. Barry Bresnihan, Anne O'Connell. Department of Rheumatology, St Vincent's Hospital, Dublin.

Neurological and psychiatric manifestations commonly occur in systemic lupus erythematosus (SLE). A prospective study of higher cerebral function was undertaken to determine whether SLE may result in progressive intellectual impairment. The standard WAIS technique was employed to assess 21 young women with stable SLE. Premorbid full-scale IQs were estimated and compared with measurements of full-scale, verbal, and performance IQs, and verbal and visual memories, obtained both at the onset of the study and after one year. Control subjects and patients with rheumatoid arthritis were also studied.

At initial testing patients with SLE did not differ significantly from controls. However, 3 SLE patients were identified in whom there was sustained reduction of full-scale IQ over one year when compared with the premorbid estimates. In addition these patients demonstrated many other psychometric features of organic brain damage. Of interest, only one of these patients had clinically overt neuropsychiatric disease. Several factors were examined, including a history of cerebral disease, disease duration, number of systems involved, serological abnormalities, and corticosteroid dosage, which did not appear to affect intellectual function.

In conclusion, most SLE patients with previous neuropsychiatric disease did not develop features of intellectual impairment. However, intellectual function did deteriorate in some, even where clinical evidence of overt cerebral disease was minimal. 
Group G streptococcal arthritis. A. Bradlow, R. G. Mitchell,* A. G. Mowat. Rheumatology and ${ }^{*}$ Baceteriology Departments, Nuffield Orthopaedic Centre, Oxford.

We describe 6 cases of Lancefield group G streptococcal arthritis. This unusual type of septic arthritis is being recognised more often in the UK. During 1972-4 no cases were reported whereas during 1975-9 20 cases were recognised. ${ }^{1}$ This may be a spurious increase asociated with wider use of streptococcal classifying techniques.

Two cases had pre-existing arthritis (one rheumatoid) with infection of a joint prosthesis. Three cases had neoplastic disease before or at the same time as septic arthritis. Skin reactions including cellulitis and scarlatiniform rash were prominent in 5 cases. Five cases responded to penicillin and the sixth, who was allergic to that drug, was cured by erythromycin.

The mode of spread of this infection is unknown, but one patient may have caught the infection from her dog. The organism occurs as a commensal in human respiratory and genital tracts and is commonly found in dogs, but the importance of man-toman or dog-to-man spread is still unclear. ${ }^{2}$ Newer streptococcal typing techniques and swabbing of patients and contacts (human and canine) may explain how this infection is spread and in particular whether dogs are an important source of human infection.

1 Public Health Laboratory Service. Communicable Disease Reports, Unpublished.

2 Parker M T. The pattern of streptococcal disease in man. Soc Appl Bacteriol Symp Ser 1978; 7: 71-106.

Who cares for young dependent people in Harrow? $\mathrm{T}$. Price, A. O. Frank. Department of Rehabilitation, Northwick Park Hospital, Harrow.

The opening of a new young disabled unit (YDU) to serve the Brent and Harrow health districts promp- ted a study to define the size and nature of the heavily disabled population of Harrow.

Information was obtained from 4 sources: (1) a waiting list for admission to the YDU, held by the area community physician; (2) the records of the community nursing service; (3) the Northwick Park Hospital physiotherapy department 'at risk' register; (4) the Harrow social services register of very severely handicapped (VSH) clients.

Table 10 shows that of $89 \mathrm{VSH}$ clients, less than $60 \%$ had ever attended their local hospital. Are they receiving the most efficient medical care? Of the 28 heaviest nursing problems in the district nearly $30 \%$ were not registered as very severely handicapped. Are they getting the benefits and social support to which they are entitled?

Most heavily disabled people live and are cared for in the community. Their optimum welfare demands closer liaison between the health and social services of the district. A rehabilitation department is well placed to provide such liaison.

A 12-month trial of auranofin versus D-penicillamine in rheumatoid arthritis. D. D. Felix-Davies, J. P. Delamere, J. R. Bateman, A. Gozzard, A. Mace, B. R. Wilkinson. East Birmingham Hospital, Birmingham 9.

D-penicillamine (DP) is of proved benefit in modifying disease activity in RA, but its use even in low dosage causes a high incidence of adverse side effects. In the search for a less toxic drug the oral gold salt auranofin (Au) $6 \mathrm{mg} /$ day was compared with DP 500 $\mathrm{mg}$ /day over 12 months in a single-blind randomised trial of 40 patients with RA (19 Au; $21 \mathrm{DP})$. Both groups were initially comparable in clinical severity and laboratory parameters, and both showed a significant decrease in $\mathrm{Rh}$ activity.

Three patients were withdrawn from the $\mathrm{Au}$ group: diarrhoea (1), disease progression (1), possibly drug-related erosive gastritis (1). In the DP

Table 10 Number of clients/patients known to be heavily handicapped and their relationship with the various caring professions

\begin{tabular}{|c|c|c|c|c|c|c|}
\hline & & \multicolumn{4}{|c|}{ Nos also on lists of } & \multirow{2}{*}{$\begin{array}{l}\text { Persons } \\
\text { registered } \\
\text { with hospital }\end{array}$} \\
\hline & & VSH & $H D P$ & $A R R$ & $Y D U$ & \\
\hline $\begin{array}{l}\text { Harrow S/S very severely } \\
\text { handicapped (VSH) } \\
\text { Harrow community nursing }\end{array}$ & 89 & 89 & 19 & 9 & 4 & 52 \\
\hline $\begin{array}{l}\text { heavily disabled patients (HDP) } \\
\text { Harrow physiotherapy }\end{array}$ & 28 & 20 & 28 & 12 & 4 & 14 \\
\hline $\begin{array}{l}\text { 'At Risk Register' (ARR) } \\
\text { YDU waiting list }\end{array}$ & 81 & 9 & 12 & 81 & 3 & 81 \\
\hline (Harrow patients) & 9 & 4 & 4 & 3 & 9 & 7 \\
\hline
\end{tabular}


group 6 patients were withdrawn: skin rashes at 4-8 weeks (4), heavy proteinuria (1), lack of compliance (1). A further 3 patients on DP had to be temporarily withdrawn: proteinuria (1), thrombocytopenia (2).

It was concluded that both drugs are effective in RA but that Au appears to be markedly less toxic. Longer term observations continue.

Alcohol consumption in arthritic patients. A. Bradlow, A. G. Mowat. Rheumatology Unit, Nuffield Orthopaedic Centre, Headington, Oxford.

There is increasing interest in the alcohol intake of patients with a variety of diseases, but little is known of alcohol consumption in arthritic patients. Alcohol abuse is a suspected cause of avascular hip necrosis, and some cases of osteoarthritis (OA) of the hip may be secondary to undetected avascular damage.

We studied alcohol consumption in 102 patients with severe primary OA of hip and 84 unselected inpatients with rheumatoid arthritis (RA) using a structured questionnaire and measurement of biochemical variables known to be influenced by high alcohol intake. Sections of femoral heads from OA patients were examined for avascular change by slab radiography. A comparison group of 'cold' orthopaedic patients without RA or symptomatic OA hip was also studied.

Alcohol consumption differed between the 3 male groups with 10 of $49(20 \%)$ OA men having a maximum admitted alcohol intake above a-Royal College-defined 'safe' threshold compared with 3 of $37(8 \%)$ RA men and 2 of $27(7 \%)$ 'comparison group' men. Women in the 3 groups showed no such trend. Strikingly, 9 RA patients $(8 \mathrm{men})$ compared with 1 OA patient had curtailed consumption because their joints were worse after even small amounts of alcohol $(p<0.05)$. One in 8 of OA and RA men claimed some pain relief from alcohol. Serum urate levels in the various sex-matched groups were similar, and none of the femoral heads from heavy drinkers with OA of hip showed avascular change.

Some RA patients therefore feel that 'alcohol and arthritis do not mix'. The higher alcohol intake among men with severe OA hip may be part of a life style that predisposes to degeneration of large joints.

Synovial fluid lactate levels in the diagnosis of septic arthritis. R. J. Newman, G. D. W. Curtis, Mary P. E. Slack. Nuffield Department of Orthopaedic Surgery, Nuffield Orthopaedic Centre, and Department of Bacteriology, John Radcliffe Hospital, Oxford.
Estimation of synovial fluid lactate levels has been advocated $^{12}$ for the rapid diagnosis of septic arthritis. Previous studies have involved special treatment of samples before transport to the laboratory, which limits their general application. A method that uses untreated samples submitted routinely has therefore been assessed. Lactate levels were measured using the UV-lactate kit (BCL, Lewes, Sussex). The centrifuged deposit of the fluid was examined by Gram stain and was cultured for aerobic and anaerobic organisms.

Three-hundred and thirteen synovial fluids were examined (Table 11). The range of the controls was $0 \cdot 78-5.46 \mathrm{mmol} / \mathrm{l}$. The level in 19 fluids from septic

Table 11 Distribution of patients and synovial fluid lactate levels

\begin{tabular}{lccl}
\hline Diagnosis & $\begin{array}{l}\text { No. of } \\
\text { fluids }\end{array}$ & $\begin{array}{l}\text { Lactate } \\
\text { Mean }\end{array}$ & $\begin{array}{l}\text { (mmol/l) } \\
\text { SD }\end{array}$ \\
\hline Septic, untreated & 9 & 11.58 & 4.04 \\
Septic, partially treated & 10 & 9.14 & 3.93 \\
\hline Viral & 5 & 2.98 & 1.94 \\
Acute osteomyelitis & 4 & 2.27 & 0.81 \\
Osteoarthrosis & 62 & 2.93 & 1.88 \\
Rheumatoid arthritis & 69 & $5 \cdot 07$ & 2.65 \\
Crystal arthropathies & 12 & 3.25 & 1.67 \\
Reiter's syndrome & 8 & 2.07 & 0.56 \\
Connective tissue disease & 15 & 2.43 & 1.24 \\
Recent trauma & 38 & 2.78 & 2.02 \\
Coagulopathies & 3 & 6.17 & 4.04 \\
Osteogenic sarcoma & 3 & 3.57 & 1.26 \\
\hline Controls & 75 & 1.85 & 0.71 \\
\hline
\end{tabular}

joints was $3.06-20.4 \mathrm{mmol} / 1$ (7.93-20.4 in 9 untreated patients; $3 \cdot 06-15.6$ in 10 partially treated patients). Septic and nonseptic fluids were best separated at $7.5 \mathrm{mmol} / \mathrm{l}$. All 4 septic arthritides with a lactate level $<7.5 \mathrm{mmol} / 1$ had received antibiotics for at least 2 days. Lactate levels $>7.5 \mathrm{mmol} / \mathrm{l}$ were found in $4 / 62$ cases of osteoarthritis, $1 / 38$ recent trauma, 1/3 coagulopathy, and 13/69 rheumatoid arthritis cases.

This study confirms that synovial fluid lactate levels are raised in septic arthritis, but may also be raised in a variety of noninfective conditions. An elevated level is therefore compatible with rather than diagnostic of sepsis, but the value of the test lies in excluding infection in untreated patients with synovial fluid lactate $<7.5 \mathrm{mmol} / \mathrm{l}$.

1 Brook I, Reza M J, Bricknell K S, Bluestone R, Finegold S M. Arthritis Rheum 1978; 21: 774.

2 Mossman S S, Coleman J M, Gow P J. NZ Med J 1981; 93: 115. 
The influence of primary osteoarthritis (OA) on the development of secondary OA. Michael Doherty, Paul Dieppe, Iain Watt. Departments of Medicine and Radiodiagnosis, Bristol Royal Infirmary, Bristol BS2 8HW.

Post-traumatic OA is thought to be a disease subset depending on the type and severity of the injury (syn. 'secondary' OA). Using meniscectomy as a human model of joint damage we have investigated the influence of generalised disease on secondary OA.

The hands and knees of 150 patients who had undergone unilateral meniscectomy were $x$-rayed at a mean postoperative interval of 24.7 years. OA changes in the knees were graded $0-3$ for each compartment. Sixty-five patients had evidence of polyarticular interphalangeal OA of the hands in a pattern consistent with generalised OA (syn. 'primary' OA). Knee OA was compared in those with or without hand OA.
OA of the unoperated knee was more frequent in those with hand OA. (Knee score $>1$ in $46 \%$ of those with hand $O A$ and $18 \%$ of those without; $p<0 \cdot 01$ ). This accords with previous data, and confirmed the generalised nature of the disease.

As expected, OA scores were higher in the operated than in the unoperated knee $(\mathrm{p}<0 \cdot 01)$. However, those with generalised OA also had much more postoperative OA (mean score $3 \cdot 9 \pm 2 \cdot 2$ ) than those without (mean score $2 \cdot 7 \pm 2 \cdot 4, \mathrm{p}<0 \cdot 01$ ). Knee OA was present in $100 \%$ of patients with abnormal hands; an OA grade $>1$ was seen in $85 \%$ of generalised OA patients compared with only $52 \%$ of those without $(p<0.01)$.

This study demonstrates that 'primary' OA influences both the development and the severity of 'secondary' OA. It emphasises the multifactorial aetiology of the disease and invalidates any clear distinction between these 2 subsets.

\section{Notes}

\section{Change of Editor}

From the beginning of 1983 Professor H. L. F. Currey becomes Editor of the Annals of the Rheumatic Diseases in succession to $\mathrm{Dr} J$. T. Scott. Papers submitted for publication should be sent to The Editor, Annals of the Rheumatic Diseases, London Hospital Medical College, Bone and Joint Research Unit, Turner Street, London E1 2AD.

\section{Pathology of rheumatic diseases}

A one-day combined course for rheumatologists and pathologists will be held on the pathology of rheumatic diseases at Southmead Hospital, Bristol, on 18 February 1983. Details from Dr C. R. Tribe, Pathology Department, Southmead General Hospital, Westbury on Trim, Bristol BS10 5NB.

\section{First European Conference on Research in Rehabilitation}

The Rehabilitation Studies Unit of the University of Edinburgh is organising the First European Conference on Research in Rehabilitation in Edinburgh in April 1983 on behalf of the Society for Research in Rehabilitation (of Great Britain). The society, which was set up in Britain in
1977, now has over 200 members, and this will be its first international conference. His Royal Highness, the Duke of Edinburgh has honoured the society by agreeing to act as patron of the conference. The problems of research in this field are many and varied and it is the society's hope that this conference will give those actively engaged in research the opportunity to explore common difficulties and share knowledge in a multiprofessional, international setting. Applications are being invited from members of all the professions concerned with research into the care of disabled people-doctors, occupational therapists, physiotherapists, speech therapists, rehabilitation engineers, nurses, clinical psychologists, social workers, etc. The convener of the scientific programme is Professor Cairns Aitken, of the University of Edinburgh, and the theme of the conference will be 'Measurement of outcome in rehabilitation'. Psychosocial as well as physical problems will be covered and there will be an exhibition of aids and equipment for disabled people. Further information from Mrs M. Brough, Executive Officer, Rehabilitation Studies Unit, Princess Margaret Rose Orthopaedic Hospital, Fairmilehead, Edinburgh EH10 7ED (tel. 031445 4123, ext. 316).

\section{Biomechanical aspects of spine}

An annual day conference on biomechanical aspects of the spine will be held at Littlewood Hall, General Infirmary, Leeds, on 7 January 1983. Details from Mrs M. Turner, Rheumatism Research Unit, School of Medicine, 36 Clarendon Road, Leeds LS2 9PJ. 